\title{
CME
}

\section{Introduction to laparoscopy}

\section{Know your laparoscopy stack}

K C D P Silva ${ }^{a}$, W Gankanda ${ }^{b}$, P Randombage ${ }^{b}$

Key words: laparoscopy stack, insufflator, video processor, light source, monitor

\section{Introduction}

Laparoscopic stack is the instrument cluster used to perform laparoscopic surgeries.

The laparoscopic stack is the heart and brain of all laparoscopic surgeries ${ }^{1}$. The perfect synchronization and compatibility of its components is essential to deliver the optimum functionality. Each component of the stack is inter-connected to each other as well as to a multitude of accessories for versatility. For example, smoke production during diathermy will automatically activate smoke evacuation via the insufflator.

Having a thorough knowledge of each of the components in the stack enables the operator to optimize the surgical performance as well as troubleshoot effectively ${ }^{2}$. Appropriate instrument procurement plays a major role in establishing a fully functional operating theatre. In-depth knowledge of the instruments in the stack will facilitate this process.

\section{Components}

The main components of the laparoscopy stack are as follows (Figure 1).

1. Monitor

2. Insufflator

3. Electro-surgical generator

4. Video processor

5. Cold light source

The laparoscopic stack is arranged in such a way that the surgeon has a clear view of the display screens. The most important displays during the surgery are the insufflator and the electrosurgical generator, which should be in full view as dynamic changes in the parameters are important for patient safety. (Figure 1)

An integrated laparoscopic cart is a value addition which will contribute towards the preservation of these expensive components during use and mobility.

\section{Sri Lanka Journal of Obstetrics and Gynaecology 2020; 42: 164-169}

DOI: http://doi.org/10.4038/sljog.v42i4.7933

\footnotetext{
a Senior Lecturer, Department of Obstetrics and Gynaecology, Faculty of Medical Sciences, University of Sri Jayewardenepura, Sri Lanka.

b Senior Registrar in Obstetrics and Gynaecology, Colombo South Teaching Hospital, Kalubowila, Sri Lanka.
}

Correspondence: DS, e-mail: dammikesilva@sjp.ac.lk

(D) https://orcid.org/0000-0001-7438-4789

Received $1^{\text {st }}$ July 2020

Accepted $1^{\text {st }}$ September 2020

This is an open-access article distributed under the terms of the Creative Commons Attribution 4.0 International License, which permits unrestricted use, distribution and reproduction in any medium provided the original author and source are credited. 


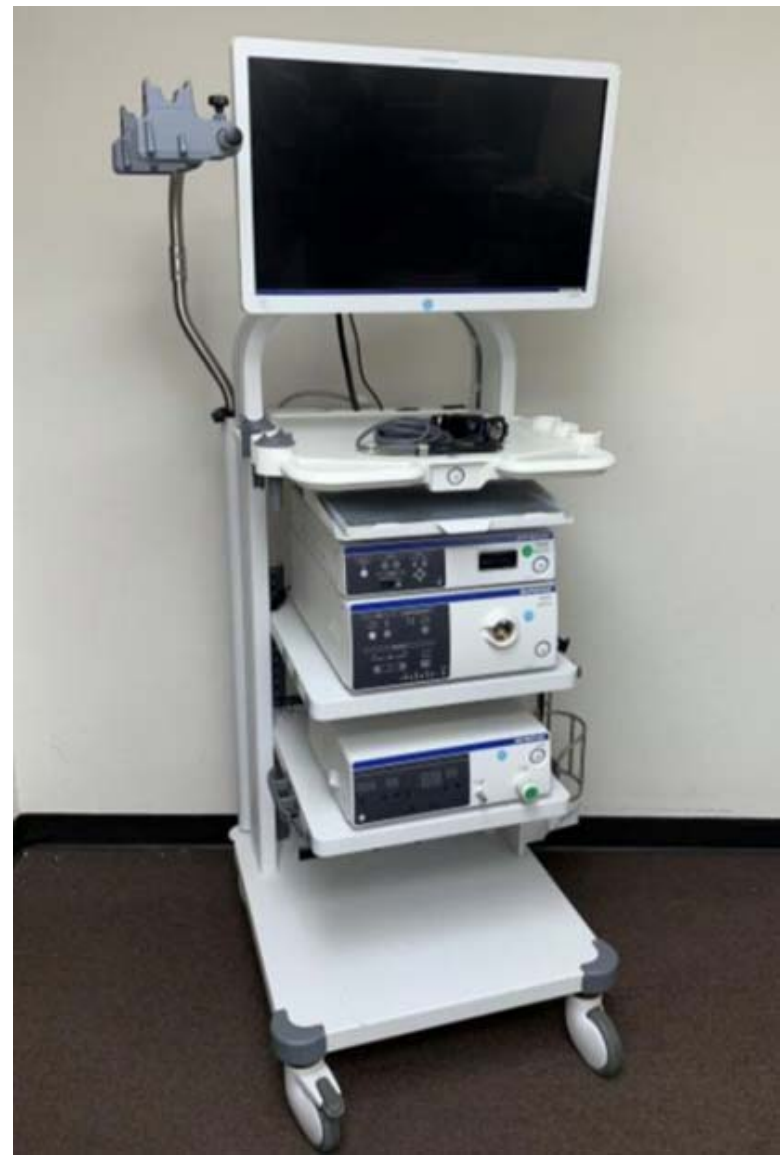

Figure 1. Laparoscopic stack including instrument cart, HD monitor, camera head, video processor, light source, insufflator, electro-surgical generator.

\section{Monitor}

Monitor displays the video signal received from a processor.

Resolution of the monitor denotes the number of pixels [smallest individual areas of a screen which displays colours] along horizontal and vertical axes respectively. Eg $-1920 \times 1200$ px where there are 1920 columns and 1200 rows [lines] of pixels.

For laparoscopy, usually monitors higher than $1920 \times 1200$ pixels of resolution are used ${ }^{3}$.

Refresh rate denotes the number of times an image is displayed on the monitor per second. It is better when the screen refresh rate is more than $24 \mathrm{~Hz}$ as the human eye perceives it as one. Therefore, as the frequency increases the blinking effect of the image decreases.

There are two different methods of refreshing the screen, namely progressive and interlaced scan. In progressive scan, the entire array of pixels is refreshed sequentially per each refresh whereas in interlaced scan, every other array is refreshed where half of the image that should be displayed is drawn on the screen per each scan. Interlaced scanning is inferior to progressive due to non-precise line overlapping producing an artifact named "combing”.

Colour depth is a measurement of the total number of colors a monitor can reproduce. Each bit can represent two colour gradients. 1 bit represents 2 colour gradients and 2 bit represents 4 colour gradients. In this manner, considering sub-pixels which can show red, green or blue basic colours, 8 bit screen means 16.8 million colours, $0 \%$ illumination of all the three sub-pixels of a pixel will show black where as $100 \%$ illumination of all the three sub-pixels will show white.

\section{D laparoscopy}

In 2D laparoscopy the depth is perceived by the brain using depth cues $^{4}$ (List 1 ).

\section{List 1: Depth cues for 3D laparoscopic view}

1. Shadows cast by illumination

2. Relative size of organs

3. Clarity of each object (where closer objects are clearer)

4. Knowledge of anatomy

5. Previous experience with laparoscopy

In 3D laparoscopy, two camera units simultaneously record images similar to binocular vision. These two feeds are projected by a single monitor viewed with 3D glasses. There are two types of 3D glasses; In active 3D glasses, a shutter mechanism alternatively shuts each eye rapidly whereas in passive 3D glasses, the monitor shows two overlapping feeds with two different polarizations where the lenses of the glass will only allow one feed intended for each eye $\mathrm{e}^{5}$.

\section{Insufflator}

The laparoscopic surgical field is created by the pneumoperitoneum. An insufflator pumps gas into the peritoneal cavity to achieve this. The pneumoperitoneum enables a clearer vision, wider surgical field, helps magnification and opens up dissection planes ${ }^{6}$. 
Most insufflators have the following in-built components (Table 1).

Table 1. Components of insufflator

\begin{tabular}{|c|c|}
\hline Component & Description \\
\hline Pinch valve & $\begin{array}{l}\text { Automatically releases gas from the pneumoperitoneum to negate the } \\
\text { excessive pressure. }\end{array}$ \\
\hline Gas outlet & Pumps out pre-heated $\mathrm{CO}_{2}$ from the insufflator via a bacterial filter. \\
\hline Gas supply indicator & Monitors the pressure of the $\mathrm{CO}_{2}$ source (gas cylinder) \\
\hline $\begin{array}{l}\text { Intra-abdominal pressure } \\
\text { indicator }\end{array}$ & Indicates the intra-abdominal pressure \\
\hline Gas flow rate indicator & Indicates the flow rate of $\mathrm{CO}_{2}(\mathrm{~L} / \mathrm{min})$ \\
\hline Gas flow rate modes & $\begin{array}{l}\text { Three gas flow rate modes are shown as low, medium and high } \\
\text { - Low - } 0.1 \text { to } 1.0 \mathrm{~L} / \mathrm{min} \\
\text { - Medium - } 1.1 \text { to } 19 \mathrm{~L} / \mathrm{min} \\
\text { - High }-19.1 \text { to } 35 \mathrm{~L} / \mathrm{min}\end{array}$ \\
\hline Volume indicator & Indicates the total amount of $\mathrm{CO}_{2}$ used \\
\hline Warning panel & Alerts for excessive intra-abdominal pressure \\
\hline Foot switch terminal & connects the foot switch to manually activate smoke evacuation \\
\hline $\begin{array}{l}\text { Electrosurgical unit } \\
\text { terminal }\end{array}$ & $\begin{array}{l}\text { Connects the electrosurgical unit to the insufflator for automatic } \\
\text { evacuation of smoke }\end{array}$ \\
\hline
\end{tabular}

$\mathrm{CO}_{2}$ is the commonest gas used in laparoscopy because of its special properties ${ }^{7}$ (List 2).

\section{List 2: Special properties of $\mathrm{CO}_{2}$ gas}

1. Inert gas

2. Natural metabolic end product

3. Dissolves in blood readily and has a high diffusion co-efficient

4. Low risk of air embolism

5. Commercially available

6. Cheap

\section{Electrosurgical generator}

Electrosurgical generator creates monopolar and bipolar diathermy energy to be used with various electrosurgical instruments. The details of electro surgical devices will be discussed in another article.

\section{Video processor}

Video processor converts the electronic data captured by the image sensor of the camera unit to a real-time video signal for viewing. High definition (HD) processors will produce the best quality images when used with HD monitors.

The processor and the light source are interconnected to automatically control the brightness as necessary as determined by the processor. 
Processor has various output ports to record or view the processed video eg. DVI, SDI, Y/C and USB (Figure 2). In addition, the processor itself can be used for compiling and printing reports when connected to a keyboard ${ }^{8}$.

The components and the main functions of the video processor are given in ${ }^{9}$ Table 2.

\section{Cold light source and cable}

The cold light source illuminates the peritoneal cavity during the laparoscopic procedure. A light source has to produce, condense and focus the light, having the ability to control the brightness while dissipating the heat produced.
A light source produces light by electric lamps which could either be Halogen, Metal Halide, Xenon or LED. LED has the best colour temperature (1700k-6000k) and the best lifespan (100000 hours). It is common to use a second Halogen light as a spare lamp in case the main lamp burns out ${ }^{9}$.

Components of the light source are given in Table 3.

Light is transmitted from the light source to the telescope by a light guide cable. Light guide cables are of two types; fiber optic and fluid light cables. Fiber optic light cables are commonly used as they are easy to handle, light-weight, flexible and autoclavable. The main disadvantage is breakage of the fibers with time, reducing clarity.

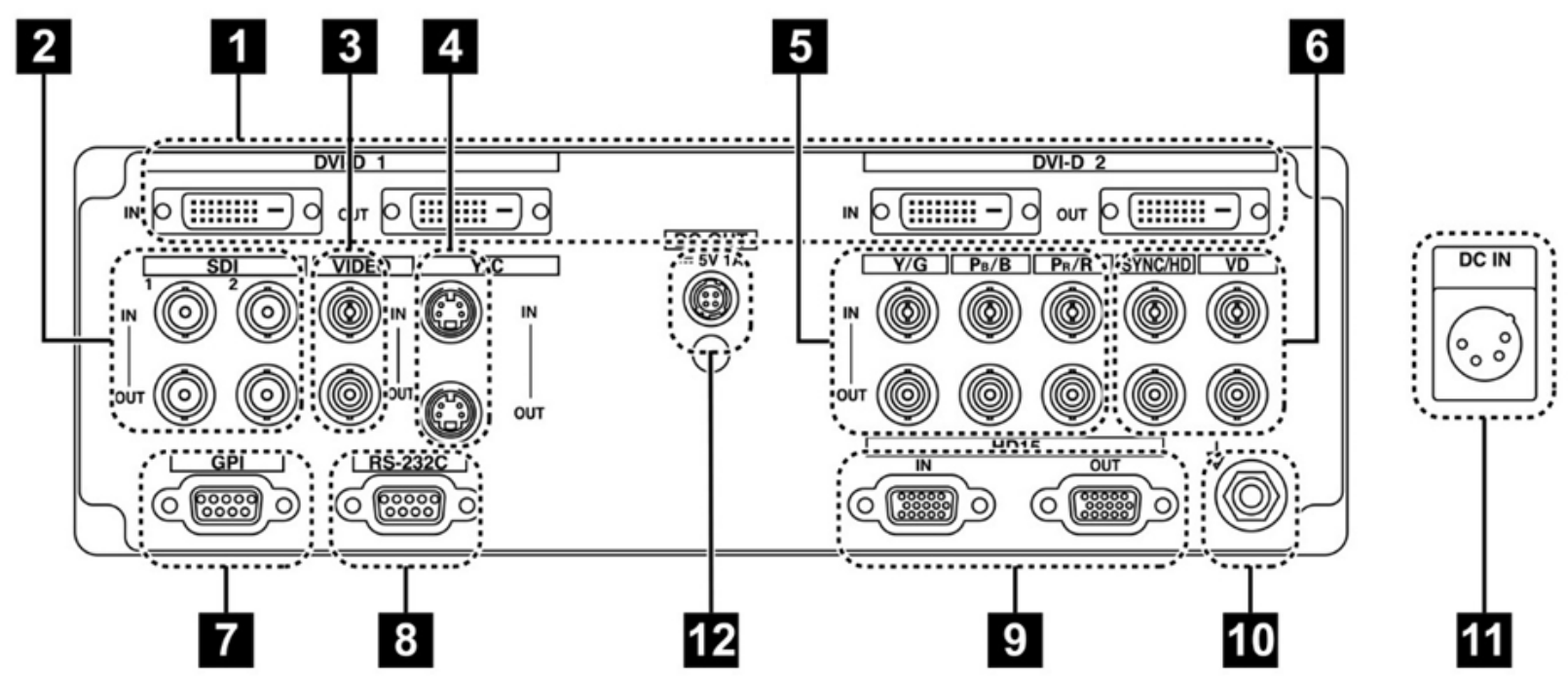

Figure 2. Video processor - rear view.

1 - DVI [Digital Visual Interface] terminals

2 - SDI [Serial Digital Interface] terminals

3 - Video terminals

4 - Y/C [Separate Video] terminals

5 - RGB [Red, Green, Blue] terminals

6 - SYNC/HD, VD terminals 
Table 2. Components of video processor

\begin{tabular}{|l|l|}
\hline Component & Description \\
\hline White balance button & $\begin{array}{l}\text { Adjusts the colour casts displayed in the monitor, so as to render images } \\
\text { which are closer to natural colours }\end{array}$ \\
\hline DVI, SDI, Y/C output ports & Transmits data from the processor to monitor or recording devices \\
\hline $\begin{array}{l}\text { Port for portable } \\
\text { memory medium }\end{array}$ & For recording still images taken during the procedure \\
\hline Port for foot pedal switch & For giving the command to capture still images \\
\hline
\end{tabular}

Table 3. Components of the light source

\begin{tabular}{|l|l|}
\hline Component & Description \\
\hline Output socket & Connects the light guide cable to the light source \\
\hline Lamp indicators & Indicates whether the lamp is on or off \\
\hline Brightness intensity indicator & Indicates the operating brightness of the lamp \\
\hline $\begin{array}{l}\text { Manual brightness adjustment } \\
\text { buttons }\end{array}$ & Controls the brightness level manually \\
\hline Lamp usage indicator & Indicates how many hours the lamp has been used. \\
\hline
\end{tabular}

\section{Conclusion}

A proper understanding of the components constituting the laparoscopic stack will enable the surgeon to perform surgery efficiently and safely.

An article on electrosurgery in laparoscopy will follow this article.

\section{Acknowledgement}

We would like to express gratitude to the Director and theatre staff of operation theatre B, Colombo South Teaching Hospital, Kalubowila, Sri Lanka.

\section{References}

1. Austen C, Govind A. Diagnostic 14 Laparoscopy. How to Perform Oper Proced Obstet Gynaecol. 2020.
2. Siddaiah-Subramanya M, Nyandowe M, Tiang KW. Technical problems during laparoscopy: a systematic method of troubleshooting for surgeons. Innov Surg Sci [Internet]. 2017; 2(4): 233-7. Available from: https://www.degruyter.com/ view/journals/iss/2/4/article-p233.xml

3. Wilhelm D, Reiser S, Kohn N, Witte M, Leiner U, Mühlbach L, et al. Comprehensive evaluation of latest 2D/3D monitors and comparison to a custom-built 3D mirror-based display in laparoscopic surgery. In: Woods AJ, Holliman NS, Favalora GE, editors. Stereoscopic Displays and Applications XXV [Internet]. SPIE 2014; 139-52. Available from: https://doi.org/10.1117/12.2040040

4. Sakata S, Grove PM, Hill A, Watson MO, Stevenson ARL. Impact of simulated threedimensional perception on precision of depth judgements, technical performance and perceived 
workload in laparoscopy. Br J Surg [Internet]. 2017/04/20. 2017; 104(8): 1097-106. Available from: https://pubmed.ncbi.nlm.nih.gov/28425560

5. Harada H, Kanaji S, Hasegawa H, Yamamoto M, Matsuda Y, Yamashita K, et al. The effect on surgical skills of expert surgeons using 3D/HD and 2D/4K resolution monitors in laparoscopic phantom tasks. Surg Endosc [Internet]. 2018; 32(10): 422834. Available from: https://doi.org/10.1007/s00464018-6169-1

6. Ren $\mathrm{H}$, Tong $\mathrm{Y}$, Ding $\mathrm{X}-\mathrm{B}$, Wang $\mathrm{X}$, Jin S-Q, Niu $\mathrm{X}-\mathrm{Y}$, et al. Abdominal wall-lifting versus $\mathrm{CO} 2$ pneumoperitoneum in laparoscopy: a review and meta-analysis. Int J Clin Exp Med [Internet]. 2014; 7(6):1558-68. Available from: https://pubmed. ncbi.nlm.nih.gov/25035780
7. Neuhaus SJ, Gupta A, Watson DI. Helium and other alternative insufflation gases for laparoscopy. Surg Endosc [Internet]. 2001; 15(6): 553-60. Available from: https://doi.org/10.1007/ s004640080060

8. Murad FM, Banerjee S, Barth BA, Bhat YM, Chauhan SS, Gottlieb KT, et al. Image management systems. Gastrointest Endosc [Internet]. 2014; 79(1): 15-22. Available from: https://doi.org/ 10.1016/j.gie.2013.07.048

9. Berber E, Siperstein AE. Understanding and optimizing laparoscopic videosystems. Surg Endosc [Internet]. 2001; 15(8): 781-7. Available from: https://doi.org/10.1007/s004640000391

10. Mishra RK. Textbook of practical laparoscopic surgery. JP Medical Ltd; 2013. 